\title{
Letter to the editor: An ultrasound observation study on the levator hiatus with or without diastasis recti abdominis in postpartum women?
}

\author{
I-Chieh Sung ${ }^{1} \cdot$ Ching-Ju Shen ${ }^{1,2} \cdot$ Cheng-Yu Long ${ }^{1,2}$ (I)
}

Received: 23 September 2021 / Accepted: 5 October 2021 / Published online: 29 November 2021

(c) The International Urogynecological Association 2021

\section{To the Editor,}

We read with interest the recent article entitled "An ultrasound observation study on the levator hiatus with or without diastasis recti abdominis in postpartum women" by Tian, Peng et al. However, we have several queries [1]. In their study, they stated that DRA is expected to more easily occur among leaner women because of the protective effects bestowed by abdominal wall fat, though in their study they found slightly increased body weight in the DRA group compared to the non-DRA group. However, we reviewed a few studies discussing risk factors of DRA, and most stated that obesity increases the risk of DRA [2-4]. The higher the BMI is, the higher the risk of DRA. The possible reason is that obese people usually have more adipose tissue in the abdominal cavity, resulting in more abdominal contents and pressure on the abdominal wall, which in turn causes the separation of the rectus abdominis. In addition, obesity may occur at the same time as muscle loss. Therefore, obese people generally have weak abdominal wall muscles, which also contributes to the occurrence of DRA [3].

They also stated that CS patients have more prevalent associations between urinary frequency and DRA, possibly due to complications from cesarean section. However, they did not mention in the article what procedure specifically was associated with urinary frequency when patients in both groups had undergone cesarean section. We would sincerely like to know what they suggested to cause this difference

Cheng-Yu Long

urolong@yahoo.com.tw

1 Department of Obstetrics and Gynecology, Kaohsiung Medical University Hospital, Kaohsiung Medical University, Kaohsiung, Taiwan

2 Department of Obstetrics and Gynecology, Kaohsiung Medical University, Kaohsiung, Taiwan between the DRA and non-DRA group patients who underwent cesarean section.

Last but not least, when documenting the clinical symptoms, they did not differentiate between stress and urgency urinary incontinence. However, it seems to us that this is important since parity is associated with SUI rather than UUI [5].

\section{Declarations}

Conflict of Interest The authors declare that they have no conflict of interest.

\section{References}

1. Tian P, Liu DM, Wang C, Gu Y, Du GQ, Tian JW. An ultrasound observation study on the levator hiatus with or without diastasis recti abdominis in postpartum women. Int Urogynecol J. 2021;32(7):1839-46. https://doi.org/10.1007/ s00192-021-04783-1.

2. Doubkova L, Andel R, Palascakova-Springrova I, Kolar P, Kriz J, Kobesova A. Diastasis of rectus abdominis muscles in low back pain patients. J Back Musculoskelet Rehabil. 2018;31(1):107-12. https://doi.org/10.3233/BMR-169687.

3. Wu L, Gu Y, Gu Y, et al. Diastasis recti abdominis in adult women based on abdominal computed tomography imaging: Prevalence, risk factors and its impact on life. J Clin Nurs. 2021;30(3-4):51827. https://doi.org/10.1111/jocn.15568.

4. Cavalli M, Aiolfi A, Bruni PG, et al. Prevalence and risk factors for diastasis recti abdominis: a review and proposal of a new anatomical variation. Hernia. 2021;25(4):883-90. https://doi.org/10. 1007/s10029-021-02468-8.

5. Berek JS, Berek DL. Berek \& Novak's gynecology (Sixteenth edition). Philadelphia: Wolters Kluwer; 2020.

Publisher's note Springer Nature remains neutral with regard to jurisdictional claims in published maps and institutional affiliations. 